IZA DP No. 7221

Quasi-Hyperbolic Time Preferences and their Intergenerational Transmission

Fabian Kosse

Friedhelm Pfeiffer

February 2013 


\title{
Quasi-Hyperbolic Time Preferences and their Intergenerational Transmission
}

\author{
Fabian Kosse \\ BGSE, University of Bonn \\ and IZA \\ Friedhelm Pfeiffer \\ Centre for European Economic Research (ZEW), \\ University of Mannheim and IZA
}

\section{Discussion Paper No. 7221 \\ February 2013}

\author{
IZA \\ P.O. Box 7240 \\ 53072 Bonn \\ Germany \\ Phone: +49-228-3894-0 \\ Fax: +49-228-3894-180 \\ E-mail: iza@iza.org
}

Any opinions expressed here are those of the author(s) and not those of IZA. Research published in this series may include views on policy, but the institute itself takes no institutional policy positions. The IZA research network is committed to the IZA Guiding Principles of Research Integrity.

The Institute for the Study of Labor (IZA) in Bonn is a local and virtual international research center and a place of communication between science, politics and business. IZA is an independent nonprofit organization supported by Deutsche Post Foundation. The center is associated with the University of Bonn and offers a stimulating research environment through its international network, workshops and conferences, data service, project support, research visits and doctoral program. IZA engages in (i) original and internationally competitive research in all fields of labor economics, (ii) development of policy concepts, and (iii) dissemination of research results and concepts to the interested public.

IZA Discussion Papers often represent preliminary work and are circulated to encourage discussion. Citation of such a paper should account for its provisional character. A revised version may be available directly from the author. 
IZA Discussion Paper No. 7221

February 2013

\section{ABSTRACT \\ Quasi-Hyperbolic Time Preferences and their Intergenerational Transmission}

This study explores the intergenerational transmission of time preferences and focuses on the question which specific aspects of mother's time preference are related to her preschool child's ability to delay gratification. We provide a new procedure for assessing the parameters of a "quasi-hyperbolic" discount function (Laibson, 1997) using two trade-off experiments. We apply the procedure to a sample of 213 mother-child pairs and show that especially mother's beta parameter is related to her preschool child's ability to delay gratification.

JEL Classification: D90, D10

Keywords: intergenerational transmission, time preference, quasi-hyperbolic discounting, preschool children

Corresponding author:

Fabian Kosse

Bonn Graduate School of Economics

University of Bonn

Kaiserstraße 1

53113 Bonn

Germany

E-mail: kosse@uni-bonn.de

\footnotetext{
"We would like to thank the Leibniz Association (LA) for supporting this study in the research network "Noncognitive Skills: Acquisition and Economic Consequences". We furthermore thank Ernst Fehr, Jürgen Schupp, Katharina Spieß and Gert Wagner for collaboration in the mother-child pilot study. The views expressed in this article are those of the authors and do not necessarily reflect the views of the LA or our collaborators. The usual disclaimer applies.
} 


\section{Introduction}

The drivers of individual decision-making are hypothesized to be intergenerationally transmitted (Bisin and Verdier, 2008, among others). Recent studies provide initial empirical evidence that preferences and beliefs are transferred from generation to generation in a very specific and often precise way. While relatively much is known concerning risk and trust related behaviour, less seems to be known concerning intertemporal decision making (Dohmen et al., 2012, among others).

For instance, risk attitudes towards health are strongly correlated between parents and children, whereas parents' willingness to take risk in health aspects is not correlated to their children's willingness to take risk in career aspects. Knowles and Postlewaite (2005) estimate an intergenerational correlation of saving behaviour in a life-cycle model and suggest that the underlying driver is the transmission of time preference. Bartling et al. (2010) and Kosse and Pfeiffer (2012) provide some initial evidence that mother's discounting behaviour is related to their preschool children's ability to delay gratification. Findings indicate that the mother's short-run discounting is a better predictor for children's self-control than her long-run discounting behaviour.

In this paper we contribute to the literature on intergenerational preference transmission by exploring the intergenerational transmission of the two fundamental parameters of a specific discrete-time discount function called “quasi-hyperbolic” (Laibson, 1997) or $\beta-\delta$ ("betadelta”) discount function (McClure et al., 2004).

In a first step we propose a new straightforward procedure to assess individual values of $\beta$ and $\delta$. In a second step we explore the relationship between the two parameters of quasihyperbolic discounting of mothers and the intertemporal behaviour of their preschool children, measured in a short-run patience paradigm. Based on the experimental data from a 
mother-child pilot study (see Bartling et al., 2010), our Probit estimates demonstrate that especially mother's beta $(\beta)$ parameter is related to her preschool children's ability to delay gratification.

\section{Assessing quasi-hyperbolic preferences with experimental data}

A calculation procedure is proposed which requires information on two indifference pairs per individual to obtain individual values of $\beta$ and $\delta$. The indifference pairs should concern the choice between a fixed smaller-sooner reward (SS) which has no delay $(t=0)$ and distant larger-later rewards $\left(L L_{i}^{*}(t)\right)$ with two different delays $\left(t=\left\{\tau_{1}, \tau_{2}\right\}\right.$ with $\tau_{1}$ and $\left.\tau_{2}>0\right)$. For each indifference pair it holds that $U(S S, \ldots)=U\left(L L^{*}(t), \ldots\right)$. As in Laibson (1997), a timeseparable utility function for one present period $(t=0)$ and one future period $(t>0)$ may be written as $U\left(c_{0}, c_{t}\right)=u_{0}\left(c_{0}\right)+\beta \delta^{t} E\left[u_{t}\left(c_{t}\right)\right]$ where $u(c)$ is the instantaneous utility received from consumption of $c$. In this formulation, $\beta$ matters relatively more for short delays and represents short-run patience. The relative weight of the discount parameter $\delta$ increases with the delay and indicates long-run patience. We assume a local-linear instantaneous utility function and that a relatively moderate monetary shock provides a utility jolt in that period in which it is received. Therefore, in a situation of indifference concerning $S S$ and $L L$, it holds that

$$
\begin{aligned}
& u_{0}\left(c_{0}\right)+E[S S] \cdot u_{0}{ }^{\prime}\left(c_{0}\right)+\beta \delta^{t} E\left[u_{t}\left(c_{t}\right)\right] \\
& =u_{0}\left(c_{0}\right)+\beta \delta^{t}\left(E\left[u_{t}\left(c_{t}\right)\right]+E\left[L L^{*}(t)\right] \cdot E\left[u_{t}{ }^{\prime}\left(c_{t}\right)\right]\right)
\end{aligned}
$$

If there is no uncertainty concerning the rewards $\left(E[S S]=S S ; E\left[L L^{*}(t)\right]=L L^{*}(t)\right)$ and if expected instantaneous marginal utility from the future period equals the instantaneous marginal utility from the present period $\left(u_{0}{ }^{\prime}\left(c_{0}\right)=E\left[u_{t}{ }^{\prime}\left(c_{t}\right)\right]\right)$, equation (1) simplifies to $S S=\beta \delta^{t} L L^{*}(t)$. Using indifference pairs with two different delays $t=\left\{\tau_{1}, \tau_{2}\right\}$, there are two 
equations with two unknown parameters. Solving the two equations delivers individual values of $\beta$ and $\delta$ :

$$
\begin{aligned}
& \beta_{i}=S S\left(\frac{L L_{i}^{*}\left(\tau_{2}\right)^{\tau_{1}}}{L L_{i}^{*}\left(\tau_{1}\right)^{\tau_{2}}}\right)^{\frac{1}{\tau_{2}-\tau_{1}}} \\
& \delta_{i}=\left(\frac{L L_{i}^{*}\left(\tau_{1}\right)}{L L_{i}^{*}\left(\tau_{2}\right)}\right)^{\frac{1}{\tau_{2}-\tau_{1}}}
\end{aligned}
$$

How realistic are the assumptions? Irrespective of the choice, participants received the payments by cheque, which was sent by mail and administered by a highly credible and in Germany well-known agency. Thus, the experimental design ensured trustfulness in receiving the reward in a way that uncertainty is the same for all choices.

The assumption that marginal utility today equals the expected marginal utility on the future delivery date might not hold or might not hold for all participants. Yet, since a maximum delay of one year is employed in this study, fundamental changes in the instantaneous utility function or the consumption level may not occur. Therefore, we regard our procedure as an initial straightforward approximation of the different facets of quasi-hyperbolic discounting.

The pairs of indifference values are taken from classic choice experiments ${ }^{1}$. The sample used contains 213 mother-child pairs, who were visited by trained interviewers in their homes ${ }^{2}$.

The mothers went through a series of decisions between a fixed amount of $100 €$, available without a delay, or a higher amount, available after a delay. To implement incentivecompatible trade-offs, there was a 1-in-7 chance that the participant received the result of one

\footnotetext{
${ }^{1}$ The basic experimental design was developed by Dohmen et al. (2010).

${ }^{2}$ The sample was taken from a pretest for the German Socio-Economic Panel Study (SOEP, see Wagner et al. 2007) performed in 2008, called mother-child pilot study, see Bartling et al. (2010) and Kosse and Pfeiffer (2012). To control for confounding effects, our sample is restricted to biological mothers with German citizenship who breastfed their child and for whom all variables are available. The sample is also restricted to children who like gummy bears to ensure incentive compatibility. The restrictions reduced the number of observations from 271 to 213.
} 
randomly selected decision. The larger-later reward, starting from $100 €$ plus $2.5 \%$ p.a., increased successively by steps of $2.5 \%$ p.a., which revealed an interval in which the mother is indifferent between receiving the smaller-sooner or the larger-later reward ${ }^{3}$.

For the further calculations, the middle of this interval is used as the value of indifference $\left(L L_{i}^{*}(t)\right)$. The censored observations of mothers who either always preferred the delayed or the non-delayed reward are replaced by their conditional expectation from Tobit estimations using a set of survey questions and socio-economic variables ${ }^{4}$. Two versions of the experiment were played, the first with a delay of 6 months and the second with a delay of 12 months.

Inserting the indifference values into (2) and (3) gives us a mean (standard deviation) for $\beta_{i}$ of $0.948(0.097)$ and for $\delta_{i}$ of $0.832(0.171)$. We do not want to interpret these parameters too literally. However, they are useful to conceptually separate short-run and long-run patience and study its intergenerational transmission.

\section{Exploring the intergenerational link of quasi-hyperbolic time preferences}

The experimental setting concerning the children's patience follows the delay of gratification experiments by Mischel et al. (1989). Similar to the mothers, a trade-off between receiving a smaller-sooner reward and receiving a larger-later reward was imposed. The interviewer opened a pack of gummy bears, offered it to the child and explained that she could either eat them now or wait until the end of her mother's interview and receive an additional pack. The average interview duration was 47 minutes.

\footnotetext{
${ }^{3} 20$ steps were implemented. After the first choice of the larger-later reward it was assumed that participants prefer all higher $L L$.

${ }^{4}$ Estimates are available from the corresponding author upon request.
} 
$22.1 \%$ of the children took the smaller-sooner reward and were classified as impatient. $77.9 \%$ waited for the larger-later reward and were classified as patient. ${ }^{5}$

If there is an intergenerational relation, a patient mother is expected to have a higher probability of having a patient child. Since the delay of gratification experiment reflects a relatively short-run decision, we expect especially mother's $\beta$ to be related to her child's decision. We performed Probit analyses, with the child's patience as dependent variable and mother's $\beta$ and $\delta$ values as explanatory variables (Table 1). A set of variables was added to correct for the potential biases regarding the behaviour in the experiments, so it is controlled for mothers' wealth and children’s hungriness, among others.

Table 1: Probit analysis

\begin{tabular}{lcc}
\hline \hline & \multicolumn{2}{c}{1 Patient } \\
& $(1)$ & $(2)$ \\
\hline$\beta$ (standardized) & $.071^{* *}$ & $.073^{* *}$ \\
& $(.030)$ & $(.030)$ \\
(standardized) & .037 & .041 \\
& $(.031)$ & $(.031)$ \\
Controls: Child characteristics & Yes & Yes \\
Controls: Family characteristics & No & Yes \\
\hline Observations & 213 & 213 \\
McFadden's Pseudo R-squared & .125 & .141 \\
\hline \hline
\end{tabular}

Notes: The dependent variable is one for patient children and zero for impatient children. $\beta$ and $\delta$ are calculated according to formula (2) and (3). Controls concerning the child are age, age squared, sex, birth weight, the duration of breastfeeding, and dummies indicating the point in time since the last bigger meal. Controls concerning the family are age and age squared of the mother and dummies indicating house ownership and if the child has to share his room, both serving as proxies for wealth. The reported coefficients are average marginal effects; robust standard errors in parenthesis; ** indicate significance at the $5 \%$ level.

The results in columns 1 and 2 demonstrate that higher values of $\beta$ are associated with a higher probability that the child delays gratification. An increase of one standard deviation (0.097) of $\beta$ increases the probability that the child is patient by about $7.3 \%(\mathrm{p}=.015)$ while the correlation concerning mother's $\delta$ is also positive but not significant ( $\mathrm{p}=.177)$.

\footnotetext{
${ }^{5}$ See Bartling et al. (2010) for a detailed description of the experiment.
} 


\section{Conclusion}

The transmission process concerning time preference seems to be similarly specific as for risk preference (Dohmen et al., 2012). Combining these findings with neuroscientific evidence implies that the early intergenerational transmission of intertemporal behaviour traces back to processes in the limbic system (“ $\beta$ areas”), which drives immediate gratification and develops early in life, while the long-run orientated frontal cortex (“ $\delta$ areas”) is still developing until the end of teenage age (McClure et al., 2004; Price and Willshaw, 2000, among others). Therefore, with respect to future research, a comparable study, based on a sample of adult children and their parents, is needed to investigate the relationship between the long-run oriented $\delta$ component of parents and their offspring. 


\section{References}

Bartling, B., Fehr, E., Fischer, B., Kosse, F., Maréchal, M., Pfeiffer, F., Schunk, D., Schupp, J., Spieß, K. Wagner, G. (2010) Determinanten kindlicher Geduld - Ergebnisse einer Experimentalstudie im Haushaltskontext, Schmollers Jahrbuch - Journal of Applied Social Science Studies, 130, 297-323.

Bisin, A. and Verdier, T. (2008) Cultural Transmission, in The New Palgrave Dictionary of Economics, $2^{\text {nd }}$ ed (Eds) Steven N. Durlauf and Lawrence E. Blume, Palgrave Macmillan, New York.

Dohmen, T., Falk, A., Huffman, D. and Sunde, U. (2010) Are Risk Aversion and Impatience Related to Cognitive Ability? American Economic Review, 100, 1238-1260.

----- (2012) The Intergenerational Transmission of Risk and Trust Attitudes, Review of Economic Studies, 79, 645-677.

Knowles, J. and Postlewaite, A. (2005) Do children learn how to save from their parents, PARC Working Paper Series, 05-07,

Kosse, F. and Pfeiffer, F. (2012), Impatience among preschool children and their mothers, Economic Letters 115 (3), 493-495.

Laibson, D. (1997) Golden Eggs and Hyperbolic Discounting, Quarterly Journal of Economics, 112, 443-477.

McClure, S., Laibson, D., Loewenstein, G. and Cohen, J. (2004) Separate Neural Systems Value Immediate and Delayed Monetary Rewards”, Science, 306, 503-507.

Mischel, W., Shoda, Y. and Rodriguez, M. (1989) Delay of Gratification in Children, Science, 244, 933-938.

Price, D. and Willshaw, D. (2000) Mechanism of Cortical Development. Oxford University Press, New York, NY.

Wagner, G. G., J. R. Frick, and J. Schupp. (2007) The German Socio-Economic Panel Study (SOEP) - Scope, Evolution and Enhancements. Schmoller Jahrbuch - Journal of Applied Social Science Studies 127 (1), 139-169. 